\title{
Using qualitative risk assessment as a leading indicator for geotechnical risk in mining
}

\author{
ECF Hamman AngloGold Ashanti Australia Ltd, Australia \\ J Venter AngloGold Ashanti Australia Ltd, Australia
}

\begin{abstract}
Investor confidence is largely driven by a mining company's ability to deliver on the guaranteed return on investment. Thus, robust due diligence processes, functioning as part of a mining company's corporate governance, become essential tools to identify hazards that can impact production, assess the associated risks and introduce controls to manage the risks.

The geotechnical practitioner is tasked to manage one of the biggest risks on the mine; that of a rock mass instability. Since an instability, or collapse, need not be large to have a significant impact on production, the challenge is to develop an optimised life-of-mine design with a risk management plan that suits the risk requirements of the mining company and investors, whilst meeting acceptable, minimum safety standards.

The concept of a Geotechnical Review Board has been adopted in the industry as a vehicle to provide assurance that the geotechnical risks on a mine have been identified and are being properly managed. The review relies on external parties providing appraisals of the design and processes, and experienced oversight of the active operations. In general, these reviews tend to have a unique style; often a combination of the current, visible, critical issues on the mine and issues deemed as important by either the reviewer or a third party. Coupled with the challenge of fluidity in modern planning environments, the geotechnical practitioner is often still faced with uncertainty in the level of geotechnical risk associated with any given mine plan.

This paper introduces a geotechnical risk assessment tool that has been developed for use as a leading indicator within AngloGold Ashanti's international operations. The authors aim to provide the reader with insight into how the tool can be utilised to understand a mine's ability to proactively identify and manage geotechnical hazards, by exploring the following components:

- Introduction to a questionnaire, which is the main input, and serves as a means for the practitioner to assess the geotechnical engineering activities being conducted on the mine compared to best-practice in the industry.

- Using a qualitative geotechnical risk matrix to report the status of the primary hazard control classes and the overall geotechnical risk on the mine compared to others in the company.

- Establishing a reliability index for the geotechnical engineering system (GES) on a mine, which can be used to illustrate how the mine's GES compares to that of a project (ranging from conceptual to feasibility level), design and construction phase, operational phase, and industry best-practice.
\end{abstract}

Keywords: risk management, leading indicators, event tree, qualitative risk assessment, reliability

\section{Introduction}

The modern day mining company needs to provide banks, shareholders and insurers with guarantees that the promised return on their investment will be realised. This demands that the company has robust due diligence processes as part of their corporate governance, which can be used to identify hazards that can impact production, assess the associated risks and introduce controls to manage the risks. The reader can refer to Addendum 1 for detail on the key definitions used in this paper. 
There are two groups of geotechnical (soil, rock, and water related) risks that need to be managed on a mine. The first are those associated with discrete hazards. These are unique, individual hazards that can be named and demarcated on a hazard plan. Discrete hazards could change in impact over time as the mine plan changes, thus having the potential for being a fluid risk. The second are those associated with the geotechnical engineering design process ('design' hazards). These are holistic, process-related hazards that form components of the larger design process. Design hazards have a high level of interconnection between the different components, which is often overlooked, leading to underestimating the impact at any given time on the mine plan. Identifying and ameliorating geotechnical risk is a challenging task, which falls on the geotechnical practitioner based on a mine.

The concept of a Geotechnical Review Board (or Panel) became common practice in the mining industry after a major slope failure occurred in the south face of the Nchanga open pit in Zambia on Sunday, 8 April 2001. Over five million tonnes of failed material collapsed into the pit and 10 employees, who were working in the bottom of the pit at the time, lost their lives in this tragic accident (Silwamba \& Chileshe 2016). Since then, Geotechnical Review Boards (GRB) have become a common industry practice in all mining environments and for all mining methods, that form a crucial part in identifying, understanding and communicating geotechnical risks in mining companies. The purpose of the GRB is to provide assurance that the geotechnical risks on a mine have been identified and are being properly managed, and that due consideration is being given to geotechnical activities such as:

- Geotechnical data collection and data management.

- Design methodology and analysis (including appropriate definition of geotechnical models and domains).

- Water management.

- Engineering practices and controls (including blasting, support and reinforcement).

- Excavation stability monitoring.

- Risk management practices (including defining the required competency of geotechnical practitioners).

The aim is to evaluate the planned production for a specific life-of-mine (LOM) option, to provide an as-accurate-as-possible snapshot of the geotechnical risks as understood at the time of the review. This requires that the review be conducted in an organised manner, which implies a methodical approach to the geotechnical engineering design process and all the activities and tasks that underpin it. Experience has shown, however, that the reviews tend to have a unique style; often a combination of the current, visible, critical issues on the mine and issues deemed as important by either the reviewer or third party. Coupled with the challenge of fluidity in modern mine planning, the ever-increasing complexity of monitoring systems and the underlying assumptions in computational processes, the geotechnical practitioner is often still faced with uncertainty in the geotechnical risk associated with any given mine plan.

It is for these reasons that the authors have developed (and tested) a geotechnical risk matrix (GRM); a qualitative risk assessment based tool used to assess the level of risk associated with the management of geotechnical engineering processes on a site or project. The holistic framework on which the GRM was conceived and constructed includes the following:

- Recognise that the management of geotechnical risk on a mine requires an interdisciplinary approach consisting of engineering and engineering management tasks pertaining to the design and management of complex systems with different lifecycles. Since there are synergies with the field of systems engineering, the term 'geotechnical engineering system' (GES) has been coined to represent the geotechnical engineering design process and its interdisciplinary relationships.

- Build a tool, incorporating typical risk management processes used in the mining industry (discussed in more detail in Addendum 2 to familiarise readers with the subject matter.) 
- Allow the user to evaluate the planned production for any LOM option (or part thereof), to highlight discrete threats and opportunities within the plan, and to facilitate reporting to the mining operation in an action plan to address these threats and opportunities.

- Make use of a ranked questionnaire that provides comparative, typically achieved levels in the different activities of the GES, up to industry best-practice. In the risk calculation, the questionnaire is used to establish the likelihood, and experienced discussion between participants to assess the impact.

- Allow for the results from the qualitative risk assessment, including the status of the primary geotechnical hazard controls and the overall geotechnical risk for the mine or mining area, to be viewed in any preferred risk matrix format.

- Establish a reliability index for the GES, to demonstrate its efficiency compared to 'designs' in a project phase (ranging from conceptual to feasibility level) through to industry best-practice.

- Serve as a standard reporting document, which provides an overview of the assessed area (mine, project or orebody) that can be compared to the rest of the company, and a detailed breakdown of corrective actions to manage the risks captured with the review.

Figure 1 illustrates the concept of the GRM tool, and how the questionnaire and risk matrix components feed through into an event tree to provide the reliability index output, which serves as a leading indicator for geotechnical risk in mining.

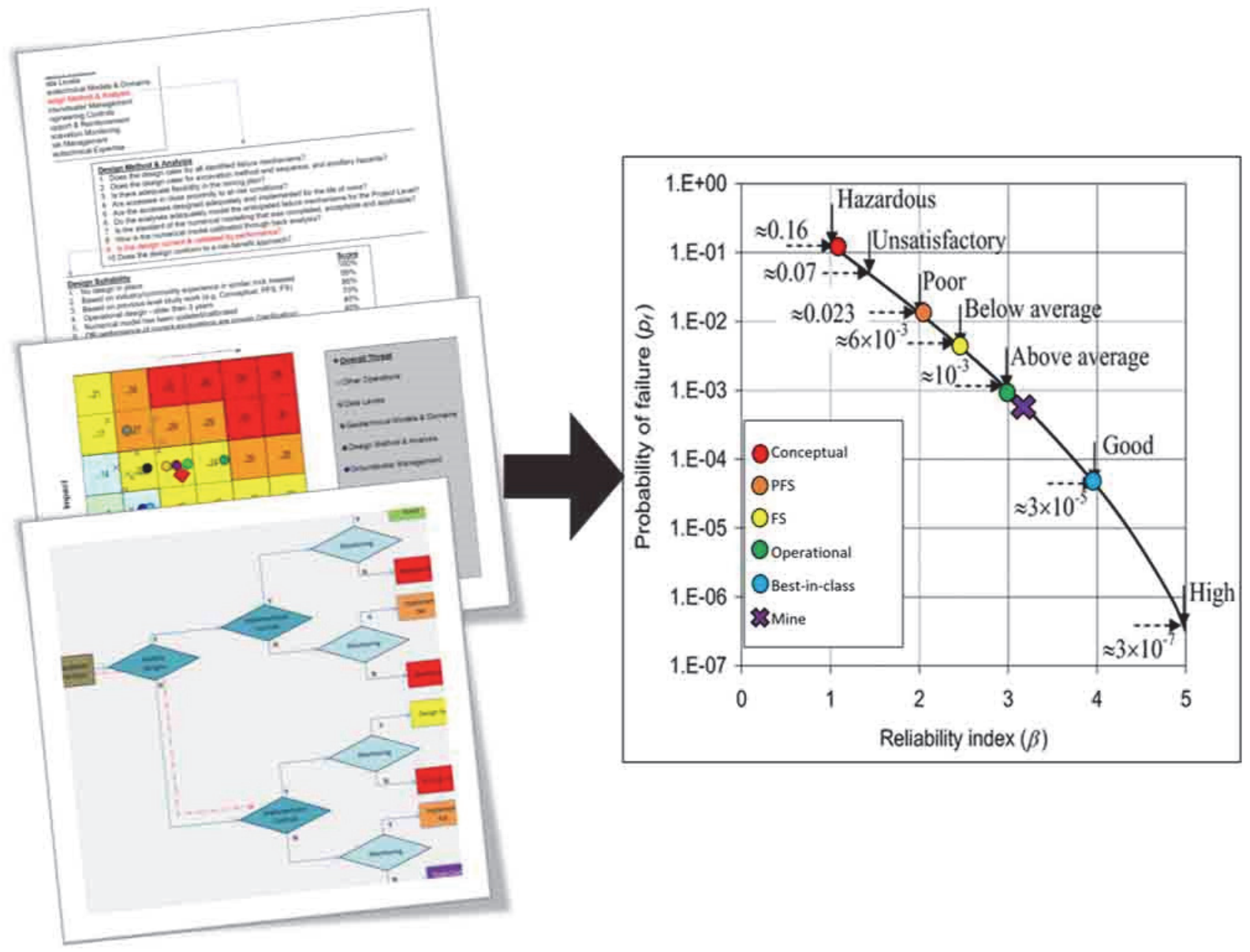

Figure 1 Geotechnical risk matrix components leading to the reliability index output 


\title{
2 Development of the geotechnical risk matrix
}

The GRM is a qualitative risk assessment tool used to assess the level of risk associated with the management of geotechnical engineering design activities on a mine. It utilises a questionnaire to establish a likelihood for the different activity groups, or hazard classes. The challenge was to ensure that the hazard classes, and subsequent questions, adhere to the views of recognised industry design methodologies and processes that are currently being utilised in the mining-based geotechnical environment, whether open pit or underground.

\subsection{Geotechnical engineering design process}

One of the first hazard assessment questionnaires (Hamman 2003, 2009) which evaluated hazards relating to a predetermined hazard class, started as an adaptation of the checklist methodology tables from the SIMRAC GAP 339 report 'Hazard Identification for Rock Engineering' (Naismith 1998). Subsequently, this questionnaire was developed further and later formed the basis of the 'Risk Management: Geotechnical Hazard Checklist' table in Read and Stacey (2009). The shear bulk of questions and interconnectedness between them demanded the development of a more refined approach.

In order to ensure that the updated version will address all aspects relating to the engineering design and execution thereof, the authors turned to work done by Bieniawski. In his paper, 'In Search of a Design Methodology for Rock Mechanics', Bieniawski $(1991,1992)$ quotes the Accreditation Board for Engineering and Technology (1987) definition of engineering design:

\begin{abstract}
"Engineering design is the process of devising a system, component, or process to meet desired needs. It is a decision-making process (often iterative), in which the basic sciences, mathematics, and engineering sciences are applied to convert resources optimally to meet a stated objective. Among fundamental elements of the design process are the establishment of objectives and criteria, synthesis, analysis, construction, testing and evaluation. In addition, sociological, economic, aesthetic, legal and ethical considerations need to be included in the design process."
\end{abstract}

The geotechnical practitioner deals with the most complex engineering design on the mine. The highly variable nature of the ground mass as a construction medium sets it apart from the engineering design of the plant and tailings storage facility. Thus, the geotechnical practitioner is also tasked to manage one of the biggest risks on the mine; that of a rock mass instability. Since an instability, or collapse, need not be large to have a significant impact on production, the challenge is to develop an optimised LOM design with a risk-management plan that suits the risk requirements of the mining company and investors, whilst meeting acceptable, minimum safety standards. This means that there needs to be a good understanding of what drives potential failure mechanisms and how these different mechanisms can be controlled in a specific design option. The final design needs to be robust, repeatable and auditable. In order to address the need for such a design process, Bieniawski $(1991,1992)$ defined a series of design principals, which was further expanded by Stacey (2009):

- Design principle 1: Clarity of design objectives and functional requirements. A statement of the 'problem' and a statement of the design objectives, taking account of any constraints that are present, to satisfy this problem, is essential to any design process. These statements clarify the design thinking at the outset. If this is not done, different engineers may interpret the problem differently and hence may design solutions for different problems.

- Design principle 2: Minimum uncertainty of geological conditions. The rock masses and conditions in which mining takes place are very variable. Mine design, therefore, takes place in an environment of considerable uncertainty. In mining, designs are often carried out with inadequate knowledge. Minimisation of uncertainty by suitable investigation of conditions will provide an environment in which more confident design can be carried out, and hence will reduce risk. 
- Design principle 3: Simplicity of design components. In terms of the simplicity principle, a design should be broken down into a series of simpler components. It is suggested here that the principle should be viewed in addition in its broadest context; simpler designs, design methods and design analyses are easier to understand and are therefore likely to be more robust. Where there is a simple way, it is to be preferred to a complex or sophisticated way, provided that it addresses the design requirements. An important step in engineering design is to develop a design model. This may be conceptual, but it is important to be able to describe the likely behaviour and the possible mechanisms of deformation and failure. Only once this has been done can appropriate design (failure) criteria be decided on, design limits be defined, required Factors of Safety or Probabilities of Failure be defined, a design model (or models) be developed, and appropriate design analysis methods be decided upon. This will ensure that the design is appropriate, and as simple as possible.

- Design principle 4: State-of-the-art practice. The implication of this principle is that up-to-date concepts, analyses and methods must be used whenever they are appropriate.

- Design principle 5: Optimisation. Risk involves numerous factors including safety, cost, productivity, seismicity, water, and labour. Therefore, to minimise risk, designs must be optimised. In addition, since conditions in which mining is taking place (economic, political, price, depth, seismicity, geology, etc.) change over time, it is likely that designs will need to be optimised again when conditions change. An optimised design will result from the evaluation of the outputs of alternative designs. Monitoring during the progress of mining will provide data that may facilitate design optimisation.

- Design principle 6: Constructability. If the design cannot be implemented safely and efficiently, it does not satisfy this principle and, therefore, is also not optimised. In such cases, it will be necessary to review the design and repeat, either partially or completely, the design methodology.

Stacey (2009) further demonstrated that a design methodology, or process, corresponding with these design principles can be summarised in 10 steps as a circular process (Figure 2).

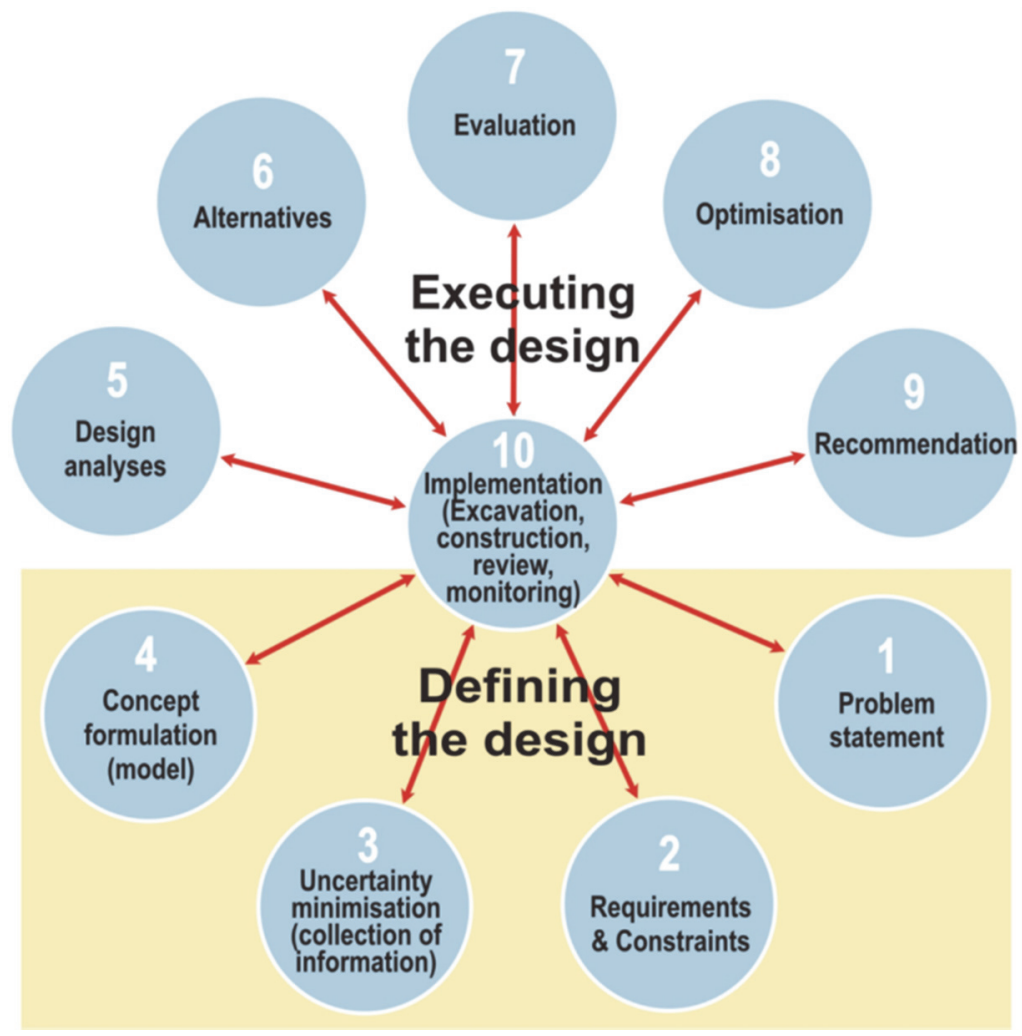

Figure 2 Geotechnical engineering circle or wheel of design (after Stacey 2009; Bieniawski 1991, 1992) 
Read and Stacey (2009) formulated a process for engineering design in open pits (Figure 3) that will, for any level of a project, involve the following steps:

- Formulation of a geotechnical model for the pit (mining) area.

- Population of the model with relevant data.

- Division of the model into geotechnical domains.

- Subdivision of the domains into design sectors.

- Design of the slope (excavation) elements in the respective sectors of the domains.

- Assessment of stability of the designed slopes (excavations) in terms of project acceptance criteria.

- Definition of implementation and monitoring requirements for the designs.

The reader will observe that there are significant synergies between the two discussed processes, with the latter providing more detail on the components feeding into the main steps.

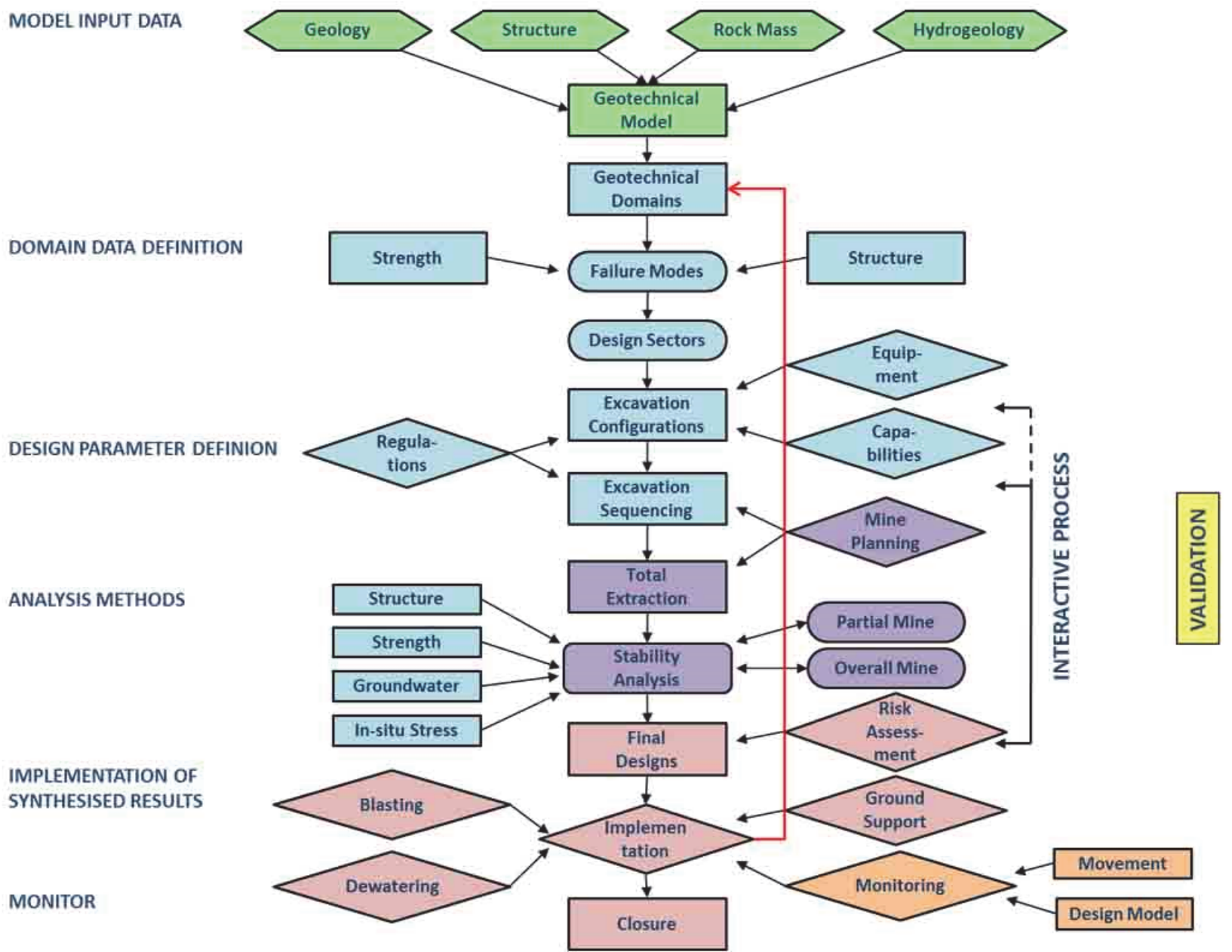

Figure 3 Geotechnical engineering design process (adopted from Read \& Stacey 2009)

Thus, these two processes formed the basis for the selection of hazard classes that was used in the updated qualitative hazard assessment questionnaire used in the qualitative risk assessment tool. 


\subsection{Hazard classes}

Hazard classes, in the context of the GRM, is a grouping of processes, activities, inputs and outputs related to the different steps in the GES. In order to facilitate the use of the GRM, nine hazard classes were defined in such a way as to cover a systematic approach, which in turn is underlain by the principles set out by Bieniawksi $(1991,1992)$. Each of the nine hazard classes have 10 questions, using a scaled ranking of 0-100\%, covering from 'nothing-in-place' to 'best-in-class' .

\subsubsection{Geotechnical expertise}

Mines are very different from one another, even though they may appear to have similarities. Simply evaluating a mine on the physical rock properties or equipment being utilised is folly. Company policies, culture, regulations, commodity price and team selection have an equal, if not bigger, influence on the appearance and operation of a mine. In essence, the difference between a mine being a success or not, lies with the people. Thus, having the right person in a role, at the right time, for a specific project, is critical.

As geotechnical practitioners, our ability to understand the problem (actual or potential) at hand, to describe it in an inclusive problem statement and put in place apt functional requirements and constraints to guide the required work, is essential to the engineering design process. Our experience to identify alternative scenarios, to optimise the preferred option, and to effectively communicate recommendations, is critical in executing an engineered design.

From a risk perspective, it is therefore important to understand what level of geotechnical expertise is required for the complexity of the site/project and what is ultimately available. This demands an understanding of where individuals, who are involved with a project or mining operation, rank in terms of competency; their education, experience, knowledge, professional affiliations and recognition in the group, or industry, all adds to competency. Furthermore, the composition of the site team, their access to principal geotechnical engineering level skills, and equipment resources is equally important.

Keeping these aspects in mind, the questionnaire developed for this class covers the following:

- Adequacy of complement and resources to manage the geotechnical risk.

- Actual and budgeted staffing levels.

- Personnel qualifications per position.

- Personnel competency per position.

- Utilisation of external consultants for design or review.

- Management structure and independency of the geotechnical decision-making.

- Value delivered by the geotechnical department.

- Ownership of geotechnical risk and associated responsibilities and accountabilities.

- Potential impact of significant staff turnover on the LOM plan.

- Level of excellence in the geotechnical engineering work being carried out.

\subsubsection{Data levels}

The problem statement and associated requirements and constraints dictate how detailed and comprehensive the collection of information, or overall data collection, will be for any specific scenario. In the questionnaire, the model input data, consisting of geology, structure, rock mass, and hydrology (Read \& Stacey 2009) is assessed in terms of the data management process flow (Figure 2) as described by Hamman et al. (2017). 
It is costly to collect most types of geotechnical data, and for many geotechnical parameters there is only limited opportunity to do so. All data follows a process flow, starting with collection and ending with a data package used during evaluations (Hamman et al. 2017). In order for data to be considered reliable, four key requirements have to be met:

- Collected to a standard, preferably industry standards (e.g. International Society for Rock Mechanics).

- Readily available and not corrupted.

- All fields completed and up-to-date.

- Properties and descriptors collected correctly.

These requirements are the same for any type of data. However, the actual fields and what is considered accurate for the properties and descriptors will change depending on the type of data (i.e. core logging, face mapping, laboratory testing, monitoring, and ground support QA/QC to name a few).

There are several underlying activities that need to be implemented to achieve these requirements. The process flow illustrated in Figure 4, developed for AngloGold Ashanti's international operations, is discussed in more detail in Hamman et al. (2017). However, a brief summary of the main points are given as Figure 4.

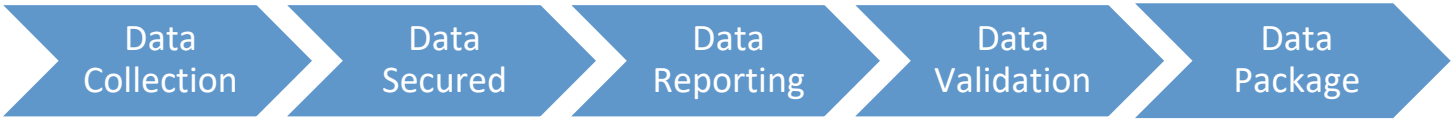

Figure 4 Data management process flow (after Hamman et al. 2017)

- Data collection: Have a robust and documented standard in place and start collecting data with constraints and validation, thus addressing the majority of the problems before the erroneous data is committed to the database. The standard should incorporate all project requirements, equipment limitations, supplier specifications and accountabilities.

- Data secured: Secure the data to ensure that it is not lost or adjusted, with a system that can log changes made to the database structure and contents.

- Data reporting: Ensure all data records are complete (the extent that the relevant records are present and populated appropriately) and all data fields are accurate (the degree that recorded data are consistent, and reflects the actual underlying information).

- Data validation: Ensure that the data is interpreted by an experienced engineer and that all the outliers are validated. Interpretive validation checks of data requires a good understanding of the different data collection methods, empirical relations and knowledge on data from similar rock masses.

- Data package: Ensure that one version of the data is readily available anywhere in the company at any given time. Accordingly, each design will have a specific data package associated with it, incorporating a date and time stamp, thereby locking in the available data and the inherent degree of reliability, now making it possible to repeat the design and audit the process.

Keeping these aspects in mind, the questionnaire developed for this class covers the following:

- Protocols for geotechnical data collection, evaluation and management.

- Geotechnical drill core data available for design.

- Face mapping data available for current excavations.

- Laboratory data available within current and planned mining limits.

- Data levels and required confidence for level of operation/project.

- 3D geological model and geological boundaries defined and current. 
- 3D structural model defined to available and existing data levels.

- Groundwater model being appropriate for the situation and current.

- Geotechnical characterisation being conducted on data.

- Ability of geotechnical database to integrate with other databases and software.

\subsubsection{Geotechnical models and domains}

A technically sound geotechnical model (obtained by merging up-to-date structural, lithological (geology), rock mass and hydrological models), similar to a geological resource model, forms the basis for geotechnical design on a mine-scale. It is important that the context against which the model is constructed is well-understood. This type of model does not attempt to predict actual geotechnical behaviour of the rock mass, but provides an estimate of the likely prevailing conditions based on an interpretation of the best currently available knowledge. During the construction of the rock mass model component, geotechnical practitioners should take due consideration of factors that may influence the distribution of any specific parameter on a mine-scale. These may include the mine's structural geological framework, rock types (lithologies), and alteration or similar ground mass characteristics.

The selection of domains and representative design sectors will be among the first engineering decisions the geotechnical practitioner will have to make. The breakdown and included detail of these representative volumes of rock (or soil) form the initial part of the concept formulation, and are largely dependent on the initial problem statement, information collected, and the competency of the practitioner doing the work.

The importance of concept formulation cannot be understated as our ability to describe the likely behaviour and the possible mechanisms of deformation and failure underpins the rest of the design process.

Keeping these aspects in mind, the questionnaire developed for this class covers the following:

- Reliability of data used in the models.

- Statistical distributions derived from available data.

- Geotechnical classification done on data.

- Availability and relevance of rock mass strength data in relation to excavations.

- Rock mass model being appropriate for the situation and current.

- Geotechnical model being appropriate for the situation and current.

- Geotechnical domains and sectors defined.

- Failure mechanisms identified for the different domains and sectors.

- Design sections and population with all relevant data.

- Integration of geotechnical model with other software.

\subsubsection{Design method and analysis}

The ability of a mining operation to provide accurate estimates of likely threats, opportunities and cost profiles is very much dependant on having a reasonable idea of the likely mining conditions over the life of the mine. The natural rock mass conditions, hydrological regime, large-scale geological structures, and the rock mass response to stress redistribution, as a result of mining, are important considerations in this regard. The identified failure mechanisms are best assessed through analytical and numerical models to evaluate the status quo against likely future mining scenarios.

In order to develop a practical rationale of model building for problem solving, it is necessary to understand the model building process. Once model building is understood, it is possible to propose a disciplined methodology 
of modelling (e.g. Basson \& Dunn 2009). Thus, the challenge is to develop a practical rationale for model building to ensure the adoption of a pragmatic, apt, effective and efficient approach to problem solving.

The aim of this class is to ensure that there is some form of justification for the model, that a suitable modelling approach and technique are considered, that the derived parameters (i.e. uncertainty type 2 'model uncertainty') are representative, and that the final model meets with the initial intent.

Ultimately, the models provide insight into what parameters to use for the geotechnical design.

Keeping these aspects in mind, the questionnaire developed for this class covers the following:

- Design, catering for all identified failure mechanisms.

- Design, catering for excavation method and sequence, and ancillary hazards.

- Adequacy of flexibility in the mining plan.

- Accesses in close proximity to at-risk conditions.

- Accesses designed adequately and implemented for the LOM.

- Adequacy of model to analyse anticipated failure mechanisms.

- Acceptability and applicability of the standard of the numerical modelling completed.

- Calibration of the numerical model through back-analysis.

- Validation of current design.

- Conformance of design to risk-benefit approach.

\subsubsection{Water management}

Water is a unique material and requires a more holistic approach when being handled onsite. Precipitation-induced surface runoff, existing water features, dewatering activities, tailings disposal, plant requirements, and water supply all add to the total volume of water to be handled and managed in an operation. Legislation imposes strict regulations on the release of water into the environment, thus having a site-wide water balance is an essential component in this class.

Keeping these aspects in mind, the questionnaire developed for this class covers the following:

- Impact of climate (precipitation) on mine.

- Adequacy of water-monitoring regime.

- Measures in place to limit/prevent inflow into and impact on mine.

- Mine surface water management system.

- Water depressurisation/dewatering system.

- Emergency plan for flooded mine scenario.

- Effectiveness of implementation of water management.

- Appropriateness of updated water balance.

- Applicability of the hydrological properties being supplied for geotechnical design.

- Water management strategy. 


\subsubsection{Support and reinforcement}

Although this class is largely applicable in the underground environment, it is becoming more prominent in larger open pits where both active and passive supporting techniques are being employed.

The establishment of ground support standards relies on a comprehensive understanding of the potential mechanisms of excavation instability, material properties, capacity of equipment and skill of operators that will be utilised during the installation process. The processes utilised to complete the design, whether empirical, analytical or numerical, need to be applicable to the mining method and excavation geometry, and need to cater for the underlying assumptions, including the loading requirements throughout the life of the excavation.

Keeping these aspects in mind, the questionnaire developed for this class covers the following:

- Support and reinforcement standards in place.

- Mine-specific design of standards.

- Structural component of design.

- Stress component of design.

- Adequacy of standard catering for expected failure mechanisms.

- Installation of support and reinforcement units.

- Use of failure data in back-analysis of support/reinforcement performance.

- Design standards and legal requirements.

- Design standards catering for planned life of excavation.

- QA/QC checks for installation standard and specification.

\subsubsection{Risk management}

This class contains several administrative controls to manage the ground control risk on an operation. The content captured in a ground control management plan (GCMP), or code of practice, needs to encompass the challenges associated with the complexity of the site. A vital part of this control is the contribution of relevant parties to the compilation/development of such a strata-control document and acceptance thereof through sign-off of the plan put forward to manage ground control hazards. Having a geotechnical hazard register that captures discrete hazards and historical operational decisions, difficulties and observations is a critical control to maintain knowledge and precedent experience.

Keeping these aspects in mind the questionnaire developed for this class covers the following:

- Geotechnical risk assessments and geotechnical risk register.

- Status and acceptance of the GCMP.

- Utilisation of site-based processes and tools.

- Improvements from Geotechnical Review Board.

- Assurance on the LOM design based on available information.

- Contribution of other technical departments to action items.

- Review checks in place for the LOM design.

- Substantiated written geotechnical reporting.

- Geotechnical induction.

- Evacuation plan and re-entry procedures. 


\subsubsection{Engineering controls}

This class involves the interaction the mine planning and production teams have with the geotechnical practitioners. Experience has shown on numerous occasions that having a good geotechnically engineered design in place, which is not executed properly, will result in a reduced return. Substandard operational practices such as poor limit blasting, sequencing, and excavation sizing, regularly introduce additional hazards into mining areas. Engineering controls are also measures of the efficiency of the GCMP and commitment the different technical teams have on adhering to practices defined in the GCMP.

Keeping these aspects in mind, the questionnaire developed for this class covers the following:

- Achievement of the planned production excavation perimeters.

- Design and implementation of blasting practices to protect the final excavation.

- Blast damage imposed on surrounding rock mass.

- Face cleaning/scaling methods implemented.

- Mitigation of rockfall hazards.

- Planned-not-mined and/or mined-not-planned areas.

- Working conditions achieved.

- Interaction between geology, mining, planning, survey, and geotechnical engineers.

- Achievement of planned schedule.

- Geotechnical considerations used on reserve conversions.

\subsubsection{Excavation monitoring}

The mining industry has a poor standard of application in the performance monitoring of excavations and structures when compared to other engineering disciplines. This class focuses on design, planning, commissioning and operating aspects of a comprehensive monitoring regime. Such a regime should cater for the failure mechanisms identified, by having instrumentation with the required sensitivity and manageable alarming options.

Keeping these aspects in mind, the questionnaire developed for this class covers the following:

- Monitoring strategy and adherence.

- Monitoring of strategic excavations identified.

- Monitoring equipment and strategy related to the expected failure mechanisms.

- Analysis of trends on existing data.

- Trigger action response plans (TARPs).

- Trigger levels related to capacity of equipment and failure mechanisms.

- Baseline data available for the mining methods and geotechnical domains.

- Unexpected failures.

- Geotechnical inspections.

- Workforce awareness of precursory activity. 


\subsection{Qualitative hazard assessment questionnaire}

Having defined the different hazard classes, the content of the original questionnaire was distributed into the relevant classes. Each class was consciously limited to 10 questions, which required further refining of the questions. This was achieved by rephrasing the questions in such a way so as to move away from 'yes/no' type answers to a predetermined scaled ranking. The ranking was also limited to 10 choices ranging from having 'nothing-in-place' to what is deemed to be currently 'best-in-class' in the industry. The rankings were then given a score ranging from $0-100 \%$, with $100 \%$ representing a definite likelihood. An example of this process flow is presented in Figure 5.

\begin{tabular}{l} 
Hazard Classes \\
\hline Data Levels \\
Geotechnical Models and Domains \\
Design Method and Analysis \\
Groundwater Management \\
Engineering Controls \\
Support and Reinforcement \\
Excavation Monitoring \\
Risk Management \\
Geotechnical Expertise
\end{tabular}

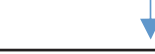

Design Method and Analysis

1 Does the design cater for all identified failure mechanisms?

2 Does the design cater for excavation method and sequence, and ancillary hazards?

3 Is there adequate flexibility in the mining plan?

4 Are accesses in close proximity to at-risk conditions?

5 Are the accesses designed adequately and implemented for the life-of-mine?

6 Do the analyses adequately model the anticipated failure mechanisms for the Project Level?

7 Is the standard of the numerical modelling that was completed, acceptable and applicable?

8 How is the numerical model calibrated through back analysis?

- 9 Is the design current and validated by performance?

10 Does the design conform to a risk-benefit approach?

\begin{tabular}{lc} 
Design Suitability & Score \\
\hline 1. No design in place & $100 \%$ \\
2. Based on industry/commodity experience in similar rock masses & $95 \%$ \\
3. Based on previous level study work (e.g. conceptual, prefeasibility study, feasibility study) & $85 \%$ \\
4. Operational design - older than three years & $70 \%$ \\
5. Numerical model has been updated/calibrated & $40 \%$ \\
6. OR performance of current excavations are proven (verification) & $40 \%$ \\
7. And operational considerations (implementation strategy) has been updated & $30 \%$ \\
8. And current LOM plan has been reviewed & $20 \%$ \\
9. Design validation has been completed and documented & $10 \%$ \\
10. Systematic design validation is part of input to LOM competent persons report & $1 \%$
\end{tabular}

Figure 5 Process flow for the qualitative hazard assessment questionnaire

Once the questionnaire has been completed, every hazard class is assessed based on the impact it may have in terms of financial, safety or litigious consequences. The impact is decided by a team of personnel from technical departments that are in the best position to understand the impact of the specific hazard class on the mine. For example, geologists will consider data levels (Section 2.2.2), and production personnel engineering controls (Section 2.2.8). The assessment makes use of the consequence rankings (for both threat and opportunity) as established on the risk matrix (refer to Figure A2-1) used by the mining group which, for this example, can be defined as per the regulatory, financial and safety threats described in Table 1 . This assessment takes into account what the maximum impact (pre-treatment) will be, should the necessary controls required by the hazard class not be present in the geotechnical engineering design process/during mining. This is to demonstrate which hazard classes have the largest potential impact in terms of threat and whether there is any opportunity that can be exploited. 
Once the questionnaire has been completed, the reviewers are provided an opportunity to comment on each question, and on the status of the hazard class as a whole. Comments can also be made to contextualise each impact assessment.

Table 1 Example of threat rating impacts

\begin{tabular}{llll}
\hline $\begin{array}{l}\text { Negative } \\
\text { impact }\end{array}$ & Regulatory & Financial & Safety \\
\hline Extreme & $\begin{array}{l}\text { Significant fine / imprisonment / loss } \\
\text { of mining right }\end{array}$ & >USD 50 million & Multiple fatalities \\
Major & $\begin{array}{l}\text { Major breach of regulation / major } \\
\text { litigation }\end{array}$ & $\begin{array}{l}\text { USD } 10 \text { million to } \\
\text { USD } 50 \text { million }\end{array}$ & $\begin{array}{l}\text { Fatality / multiple disablement / } \\
\text { occupational disease cases }\end{array}$ \\
High & $\begin{array}{l}\text { Serious breach of regulation with } \\
\text { report to authority }\end{array}$ & $\begin{array}{l}\text { USD } 1 \text { million to } \\
\text { USD 10 million }\end{array}$ & Permanent disability \\
Moderate & $\begin{array}{l}\text { Minor legal issue / non-compliance / } \\
\text { breach of regulation }\end{array}$ & $\begin{array}{l}\text { USD 100,000 to } \\
\text { USD } 1 \text { million }\end{array}$ & Temporary disability \\
Minor & $\begin{array}{l}\text { No legal issues but breach of } \\
\text { company guidelines }\end{array}$ & $\begin{array}{l}\text { USD 10,000 to } \\
\text { USD 100,000 }\end{array}$ & Medical treatment case \\
Insignificant & Negligible & <USD 10,000 & No injury \\
\hline
\end{tabular}

\subsection{Reporting results}

The results of the assessment for each of the different hazard classes are plotted on the risk matrix (Figure 6). In this example, the risk matrix is for the threat risk rating for the mine (overall threat as the red diamond) is obtained by calculating a weighted average, which can then be compared to other mines (grey ' $X$ ') in the group. A similar risk matrix is available for the opportunity risk rating.

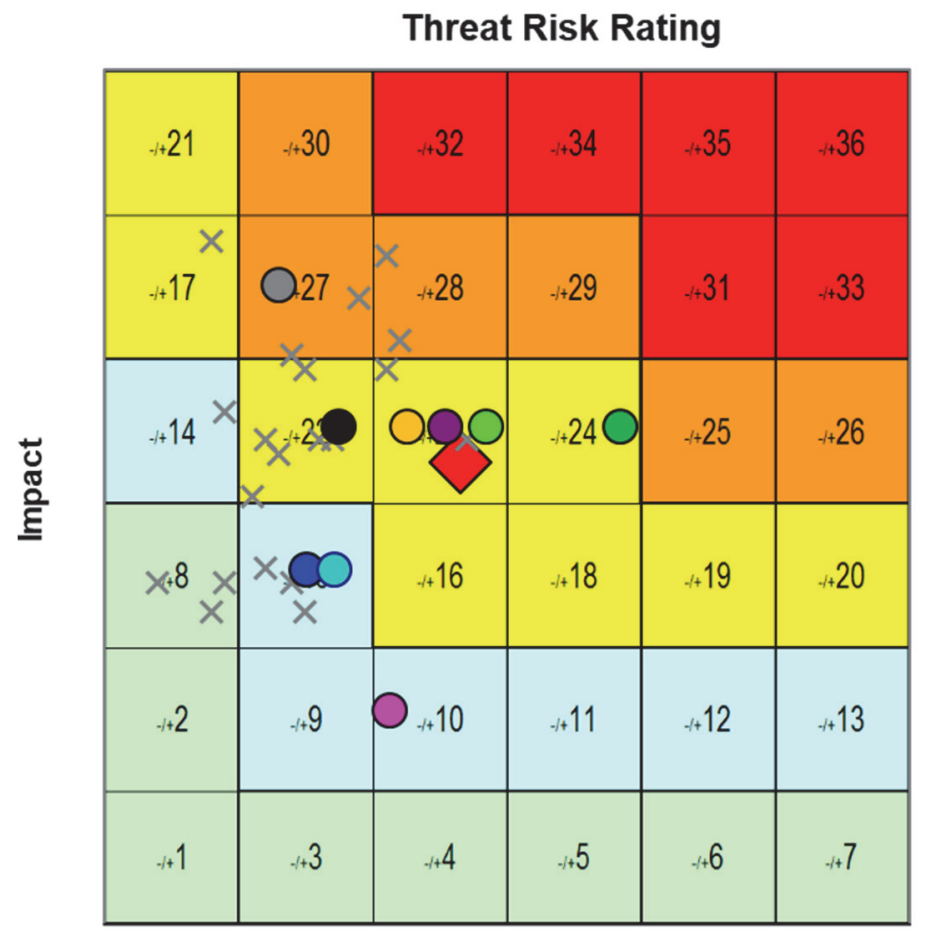

\section{Likelihood}

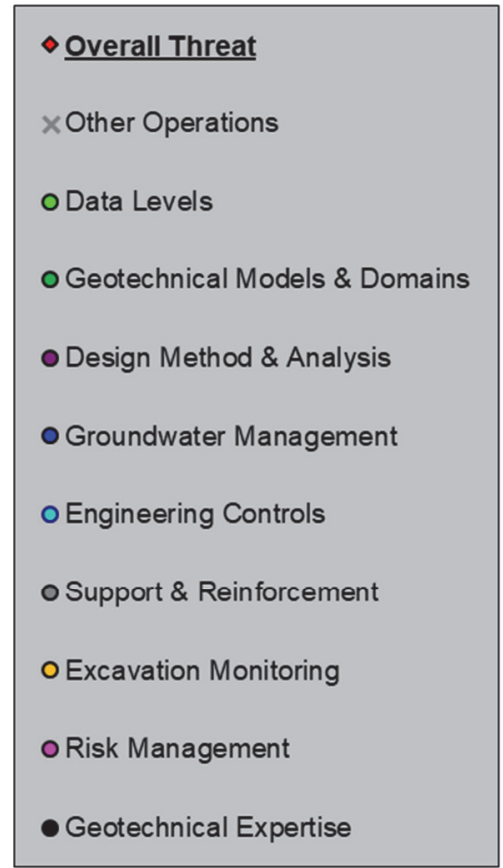

Figure 6 Example of a completed assessment plotted on the risk matrix - overall mine given by red diamonds and grey ' $X$ ' denotes results from other mine sites 
A detailed risk assessment report can be generated, which provides a summary page of the risk assessment which includes the risk matrices and backup documentation from questionnaires. This provides a detailed work list to the geotechnical practitioner of what is required at her/his mine to move to a best-in-class in all the hazard classes.

\section{Reliability index from event tree}

The authors found that, although the process described above provides a detailed view on the hazard classes and a comparative view of the overall mine performance, management still often has difficulty understanding whether their mines are capable of effectively and safely managing geotechnical risks identified. The interdependence of the defined hazard classes was a major factor, which often led to added confusion.

The calculations in the tool already catered for the level of geotechnical effort required at the different project stages (conceptual, pre-feasibility, feasibility, construction and operations) as defined by Read and Stacey (2009). Since there is already an understanding by mine management on the reliability of a design associated with different project stages, the logical choice would be to establish a means to show where the mine's geotechnical risk lies in comparison to these project stages, and to define what is deemed to be best-in-class in the industry. The authors opted to develop a process around the use of the reliability index as it provides a single number, which uses familiar risk nomenclature and can be related to published risk-acceptability criteria.

\subsection{Reliability index of geotechnical engineering systems}

The reliability index $(\beta)$ is a measure of the reliability of an engineering system that reflects both the mechanics of the problem and the uncertainty in input variables. This index was developed by the structural engineering profession to provide a measure of comparative reliability without having to assume or determine the shape of the probability distribution necessary to calculate an exact component value of the Probability of Failure (Kamien 1995).

In the case of geotechnical structures (or excavations), the reliability index is used as a "relative measure of reliability or confidence in the ability of a structure to perform its function in a satisfactory manner" (Kamien 1995). In the reliability assessment of GESs, the target reliability values presented in Table 2 are used. Thus, excavations with relatively high reliability indices will be expected to perform their function well, while excavations with low reliability indices will be expected to perform poorly and present major operational problems. If the reliability indices are very low, the excavations may be classified as hazardous.

Table 2 Target reliability indices (Kamien 1995)

\begin{tabular}{lll}
\hline $\begin{array}{l}\text { Expected } \\
\text { performance level }\end{array}$ & $\begin{array}{l}\text { Reliability index } \\
\text { beta }(\beta)\end{array}$ & $\begin{array}{l}\text { Probability of unsatisfactory } \\
\text { performance, } P_{f}=\Phi(-\beta)\end{array}$ \\
\hline High & 5 & 0.0000003 \\
Good & 4 & 0.00003 \\
Above average & 3 & 0.001 \\
Below average & 2.5 & 0.006 \\
Poor & 2.0 & 0.023 \\
Unsatisfactory & 1.5 & 0.07 \\
Hazardous & 1 & 0.16 \\
\hline
\end{tabular}

Note: The Probability of Failure (of the engineering system) is the probability that an unsatisfactory event will occur. For example, if the performance function is defined in terms of instability, and the probability of unsatisfactory performance is 0.023 , then 23 of every 1,000 potential instability scenarios will result in damage which causes a safety hazard.

A 'good' rating has been set as a best-in-class target due to the natural variability within the geotechnical environment. 
The reliability of a few subsystems or components of controls may govern the reliability of the entire system. Thus, it is important to develop a means to characterise and compare the reliability of these controls (i.e. the geotechnical hazard controls as defined with the hazard classes). An event tree is such a scenario assessment tool, which can be used to assess the probability of all controls failing during the detection and management of a geotechnical event on a site or project.

The event tree is a flow diagram where different pathway scenarios are assessed statistically by testing the effectiveness of the consecutive controls in the overall process. In this case, the process refers to the GES on a mine, which includes data collection, design analyses and implementation, as well as excavation performance monitoring. The event tree utilised in the tool stems from the fault tree analysis as published by Terbrugge et al. (2006), which has been extensively used in large open pit and underground design and operations.

\subsection{Event tree construction}

A risk/consequence analysis can be performed by using event trees developed to represent the geotechnical engineering design process. The potential interactions between the different hazard classes were assessed, and in the end the event tree (Figure 7) was refined to four control nodes and five risk outcomes:

- Foundation base input: This is a combination of data levels and geotechnical expertise. The view is that having enough correct data and competent engineering skills underpins the whole engineering process.

- Analysis designs: The aptness and level of detail in the geotechnical models and domains and the design method and analysis is symbiotic. It is the basis of the iterative design process and allows for adequate option selection.

- Implementation controls: This includes engineering controls, support and reinforcement and water management. All of these classes require interaction from other departments and hence an underlying challenge to get the work scheduled and completed to standard.

- Monitoring: There is also a symbiotic relation between risk management and excavation monitoring. It entails an understanding of how the structure is performing and whether this behaviour and the actual construction are within tolerances.

Terbrugge et al. (2006) state that subjective decisions are made by experienced persons on the likelihood of failures of the component of the slope management system as instituted on a mine. In this case, the likelihood of a particular hazard class is obtained from the tool, which is based on rankings made by technical personnel when completing the questionnaire.

Estimates of the nodes are made from either triangular or rectangular distributions. It was found that continuity in personnel and consistency in mining method provides a better control on all the hazard classes, thus warranting a triangular distribution. Historical records have shown that, over a year, the likelihood can change by up to $10 \%$, without any intervention being made. 


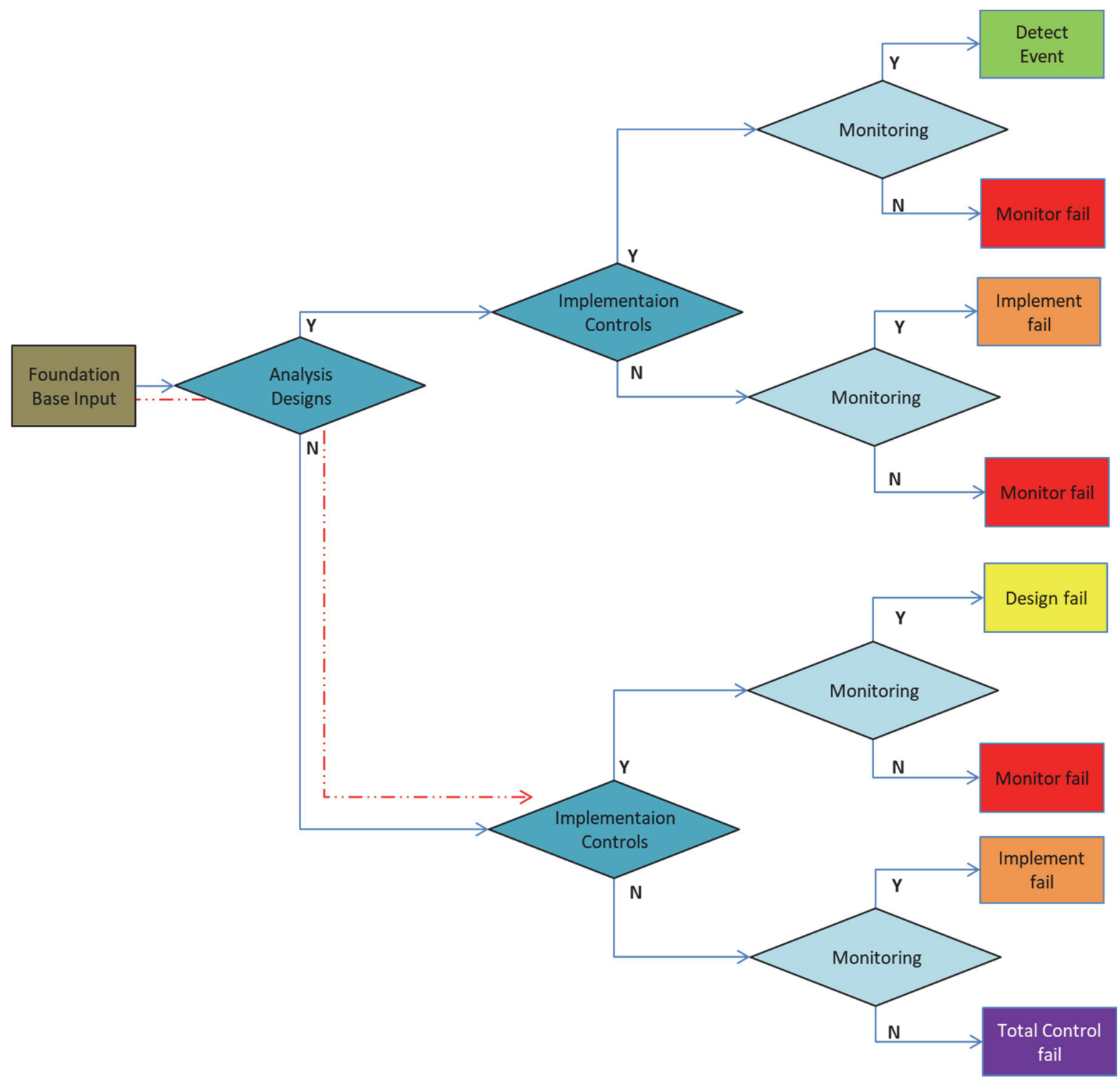

Figure 7 Event tree adopted for the likelihood data obtained from the questionnaire $-Y$ denotes success

\subsection{Reporting reliability}

In this scenario (Figure 7), an 'event' is related to any geotechnical application or incident. The risk outcomes indicate which of the control nodes failed or whether all of them failed. In the case where all the controls fail, the probability for total control failure is the probability of the GES failing. This value can be plotted so as to obtain a reliability index (Figure 8 ), which can now be reported to management to indicate where the mine stands in terms of managing geotechnical risk.

The system and outputs have been proven to be robust with results presented in the risk matrices and reliability index figures being vindicated by actual performances on mines. As a result, this qualitative risk assessment is now being used as the preferred means to measure future geotechnical risk and management on sites, thus serving as a rigorous leading indicator. 


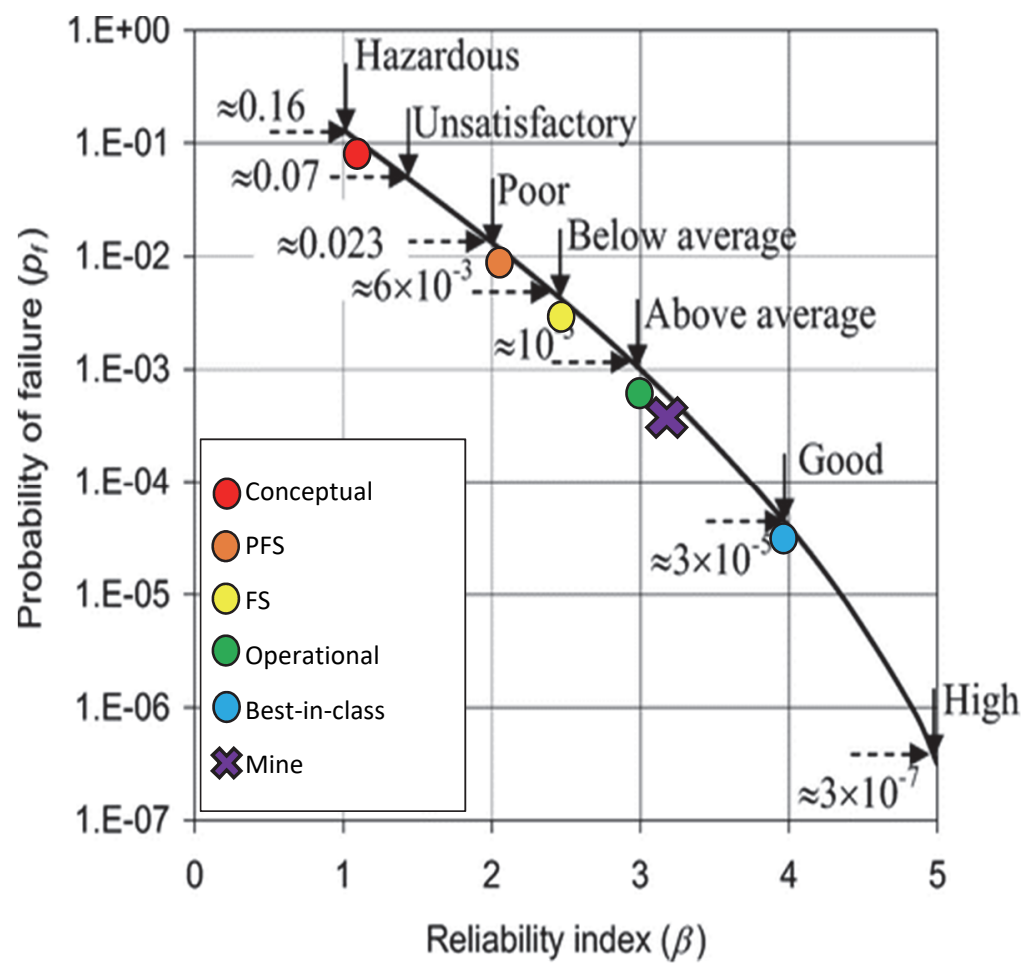

Figure 8 Reliability index targets for a geotechnical engineering system (after Kamien 1995)

Note that a 'good' rating has been set as a best-in-class target due to the natural variability within the geotechnical environment. The project stages were assessed based on the requirements specified by the 'Levels of geotechnical effort by project stage' table in Read and Stacey (2009), and the best-in-class based on obtaining a perfect score from the questionnaire.

\section{Conclusion}

The challenge was to develop a means to assess geotechnical risk on mines and for projects. The tool had to provide the reviewer with sufficient guidance on all aspects pertaining to the geotechnical engineering design process and system, and help facilitate a rigorous review. Reporting and communication of the results had to be in a format that management are familiar with, appreciates, and understands.

This led to the development of a questionnaire-based, qualitative risk assessment based on industry-accepted processes. The tool was set up to comply with industry risk-assessment guidelines and further developed to allow for the population of an event tree and calculation of a reliability index.

The GRM tool has been tested on all of AngloGold Ashanti's mines and projects, and has proven to be a robust tool to communicate risk and provide means to serve as a leading indicator for the geotechnical engineering design process.

\section{Acknowledgement}

This work has been developed through the input of various practitioners within AngloGold Ashanti, as well as industry peers. The authors gratefully acknowledge the contribution of their peers and colleagues, and the management of AngloGold Ashanti for the opportunity to present this work. 


\section{Addendum 1: Preamble definitions}

This addendum provides readers with an opportunity to familiarise themselves with the definitions of certain keywords used in the paper and the development of the geotechnical risk assessment tool.

'Harm', 'hazard', 'likelihood', 'impact' and 'risk' as used in this geotechnical review are defined as follows:

- Harm: The negative effect on people, or damage to equipment or infrastructure.

- Hazard: Something with the potential to cause harm, or source of potential harm. It can be defined as 'a condition or situation that exists in the work environment that has the potential to cause physical harm, injury and/ or damage'. In the mining environment, a potential rockfall is a hazard.

- Hazard class: Hazard classes are a way of grouping together elements that have similar properties. In the context of the tool, the hazard class is a grouping of processes, activities, inputs and outputs related to the different steps in the geotechnical engineering design process.

- Impact (or consequence): Socio-economic result or outcome of a hazard event occurring. The amount of damage/harm from the rockfall is the impact or consequence. It is important to note that the consequence for a near-miss will need to consider a situation where a minor change in circumstances can lead to an injury or fatality, or damage.

- Likelihood: Potential or probability of a hazard occurring.

$$
\text { Likelihood }=\text { Probability of event occurring } \times \text { Exposure probability }
$$

The probability of the event occurring should be established, as well as the probability that the consequence would materialise (also known as the exposure probability). These are typically determined from historical data, detailed analysis, and/or expert judgement (refer to example in section A2.3.4). The exposure is the time that people/equipment are present within range of the hazard. The probability of the event occurring is a way to measure and communicate the level of confidence in the data and analysis, and can be influenced by various drivers:

- Direct drivers include vibration, rock strength, water, disturbance (blasting, barring, impact) or structure.

- Indirect drivers include excavation size and schedule. This includes any non-conformance such as adherence to working procedures and out-of-sequence or unplanned mining.

- Risk: Likelihood that harm with a certain impact may occur from a specific hazard. Sullivan (2006) addresses the concept of risk in terms of both chance of occurrence (likelihood) and consequence, where:

$$
\text { Risk }=\text { Likelihood } \times \text { Consequence }
$$

Risk implies an assessment of the future about the likely course of events related to a hazard. Hence, risk in mining means some knowledge or experience that would lead to an understanding of both the likelihood of occurrence and consequences of a particular hazard (or hazards). Essentially, not knowing what outcome will materialise, but knowing what the distribution of possible outcomes would look like.

Risk can be described as a state of uncertainty where some possible outcomes have an effect or consequence. The likelihood of something happening that will impact on objectives is the combination of the probability of an event and its consequence. Risk could influence the achievement of certain objectives in both a negative and positive manner. Risk can be viewed as a condition in which the possibility of loss/gain exists. In some situations, risk arises from the possibility of deviation from the expected outcome or event. Risks arise as much from failing to capture business opportunities when pursuing strategic and operational objectives as it does from a threat that something bad will happen. 
The word 'risk' derives from the early Italian 'risicare', which means 'to dare'. In this sense, risk is a choice rather than a fate. In the rockfall scenario, risk relates to exposure to the danger and is defined as 'the probability of any injury, damage or loss occurring from the hazard'. The risk is that a rockfall causes harm and/or damage. The choice is then to enforce, or not, a ground support system and operational practices that 'eliminate' rockfall.

Other terms that are used throughout the paper are:

- Uncertainty: In essence it is not knowing what will happen next with confidence, and not knowing what the possible distribution looks like. Lilly (2000) expanded on the types of uncertainty originally defined by McMahon (1978):

- Type 1 - 'unknown unknown': Sullivan (2006) paraphrased a discussion with Stapledon on the concept: "We only see what we know". The majority of these types of uncertainties are from geological, hydrogeological or hydrological origin. The main contributor, geological uncertainty, embraces the unpredictability associated with the identification, geometry of and relationships between the different lithologies and structures that constitute the geological and structural models (Read 2009). For example, a weak plane not observed in a drilling program.

- Type 2 - 'model uncertainty': Model uncertainty accounts for the unpredictability that surrounds the selection process of parameters and the different types of analyses used to formulate the slope design and estimate the reliability of the pit walls. Model uncertainty exists if there is a possibility of obtaining an incorrect result even if exact values are available for all the model parameters (Read 2009). The uncertainty or variability (coefficient of variation) of the output is directly dependent on the uncertainty of the inputs (Wiles 2006):

$$
C_{\text {Output }}=\sqrt{C_{\text {Geometry }}^{2}+C_{\text {Geology }}^{2}+C_{\sigma^{f}}^{2}+C_{\text {Model }}^{2}+C_{\text {Properties }}^{2}+C_{\text {Numerical }}^{2}}
$$

where:

$$
\begin{aligned}
& \mathrm{C}_{\text {Output }}=\text { coefficient of variation of combined inputs. } \\
& \mathrm{C}_{\text {Geometry }}=\text { geometry (approximation of actual mining shapes, 2D, 3D). } \\
& \mathrm{C}_{\text {Geology }} \quad=\text { geology (lithology) } \\
& \mathrm{C}_{\text {of }} \quad=\text { pre-mining stress state (magnitude, stress ratios, orientation). } \\
& \mathrm{C}_{\text {Model }} \quad=\text { constitutive model type (elastic, plastic, fault slip) } . \\
& C_{\text {Properties }}=\text { material properties (strength, stiffness). } \\
& \mathrm{C}_{\text {Numerical }}=\text { numerical approximation (element sizes) } .
\end{aligned}
$$

All of these uncertainty inputs need to be characterised and appropriate numerical values selected. Examples include shear strength values being over-estimated, groundwater pressures in a slope ignored, or 2D model results used without cognisance of the complex 3D geometry.

- Type 3 - 'bias-variation': The unpredictability of the properties used to account for the various attributes of the geotechnical model. Typically, it includes uncertainties associated with the values adopted for rock mass and hydrogeological model parameters such as the friction angle, cohesion, deformation moduli and pore pressures (Read 2009). This leads to greater variation in the estimated design parameters. For example, the mean shear strength of a clay (e.g. friction $=10^{\circ}$ and cohesion $=20 \mathrm{kPa}$ ) does not account for a significant proportion of the material that has much less cohesion due to pre-existing movement on laminations. 
- Type 4 - 'human factor': All aspects of the engineering design process rely on human input. This uncertainty includes issues related to training, competency, communication and staffing resources. The adoption of standardised tools and behaviours is a very effective strategy in enhancing teamwork and reducing risk. The most common human errors are related to calculations or data input. An example of this is the Aberfan disaster, which was described by the tribunal chairman Edmund Davies (1967) as, "....a terrifying tale of bungling ineptitude by many men charged with tasks for which they were totally unfitted, of failure to heed clear warnings, and of total lack of direction from above."

- Type 5 - 'design change': Each year, mine designs and plans are re-assessed to cater for changes in the resources and reserves. The acceptance of a design is based on the level of reliability and all the economical, safety, environmental and social risk factors. Thus, this uncertainty relates to any change of a design without reference to geotechnical conditions and/or implications, such as the change in extraction sequence to fit financial parameters.

- Type 6 - 'excessive conservatism': In the design process, there are certain design assumptions to be defined, input parameters to be selected, and analysis interpretations to be made. All these require human intervention by the engineer. Often, these decisions are made by the engineer applying a conservative approach with each step of the process. The extent of conservatism is a function of experience.

- Reliability (data): The accuracy and completeness of all collected and/or processed data, with cognisance of the intended uses. In a data confidence context (as defined in Read 2009), reliability means that data populations are complete for the geotechnical status level (or project status level), that they are accurate, and properly address the uncertainties for the intended purposes, and from a database security perspective, are not subject to inappropriate adjustments.

- Reliability (design): In engineering terms, a specific design will represent a system (overall orebody extraction) or a component (pillar or stope) thereof. Reliability is the probabilistic assessment of the likelihood of the adequate performance of a system (or its components) for a specific period of time under proposed operating conditions (Harr 1996). As such, the probability of the success of a design is its reliability:

$$
R+p(f)=1
$$

where:

$$
\begin{aligned}
& R=\text { reliability. } \\
& p(f)=\text { Probability of Failure. }
\end{aligned}
$$

Note that reliable data does not constitute a reliable design, and vice versa.

- Confidence: This is usually expressed as a confidence level, which in turn is the probability value associated with a confidence interval. A confidence interval gives an estimated range of values, which is likely to include an unknown population parameter; the estimated range being calculated from a given set of sample data. For example, given a distribution of point load data (Figure A1-1), for a confidence level of $95 \%$, the expected value will be within a confidence interval of $7.90<\mathrm{E}[\mathrm{x}]<12.10$. The higher the confidence level, the larger the confidence interval. 


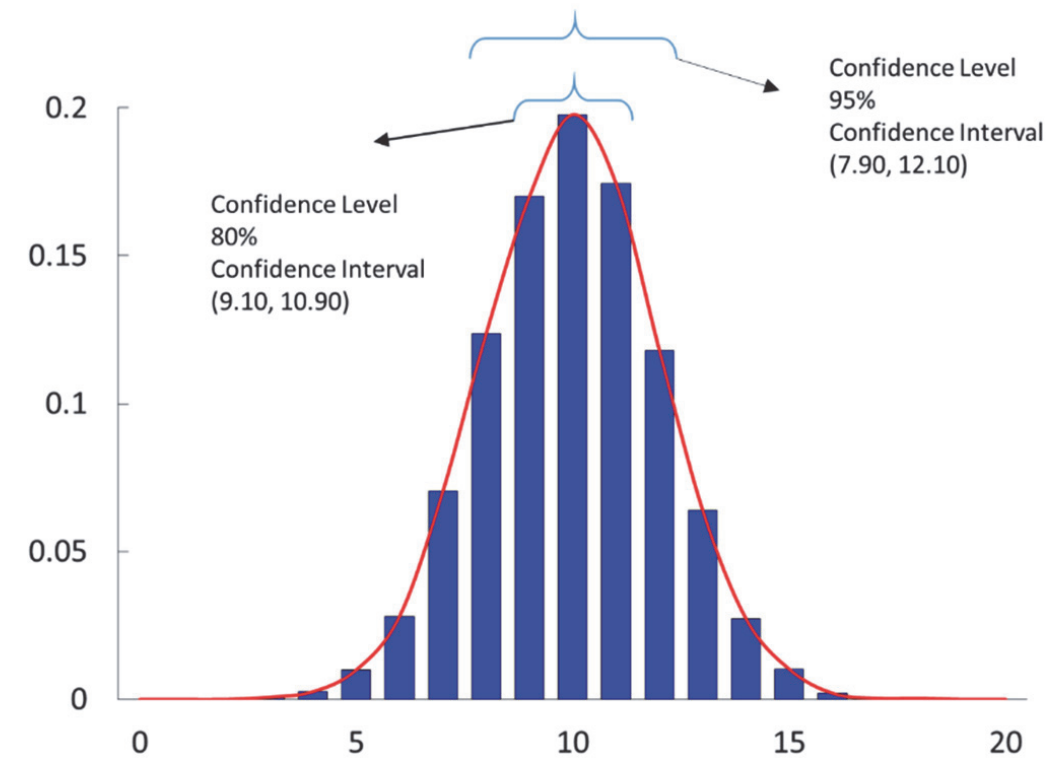

Figure A1-1 Confidence level and confidence interval for the expected value

- Risk management: The culture, processes and structures that are directed towards realising potential opportunities whilst managing adverse effects. Risk management is the identification and evaluation of actual and potential risk areas as they pertain to a mining company as a total entity, followed by a process of either termination, transfer, tolerance (acceptance), or treatment of threats, and exploitation, sharing, maximising, or enhancing opportunities.

- Risk management system: A group-wide risk management system is the combination of processes and structures that achieve the required outcomes. The system involves the systematic application of management policies, procedures and practices to the tasks of communicating, establishing the context, identifying, analysing, evaluating, treating, monitoring and reviewing risk. The risk-management system entails the planning, arranging and controlling of activities and resources to minimise the negative impacts of all risks that can be tolerated, as well as to optimise the opportunities, or positive impacts, of all risks.

- Risk treatment (control): The process of selection and implementation of measures to modify risk. An existing process, policy, device, practice or other action that acts to minimise negative risk or enhance positive opportunities. Typical controls, associated with rockfall events, include engineering, administrative and isolation. Examples of these controls include the use of ground support (reinforcement and/or surface support), engineered designs on excavation sizing/sequencing, procedures that control access, and working standards on barring.

- Near-miss: A situation that could, but for a minor change in circumstances, have led to an injury or fatality; environmental, community or social issue; financial loss or business or asset interruption, disruption or loss; reputational damage; legal and regulatory issue; or an emergency or crisis. A near-miss is an unplanned event that did not result in an incident or accident but which had the potential to do so; only a fortunate break in the chain of events prevented the incident/accident.

\section{Addendum 2: Risk management}

The underlying premise of risk management is that every business entity exists to provide value for its stakeholders. All such entities face uncertainty and the challenge for management is to determine how much uncertainty to accept as it strives to grow stakeholder value. Uncertainty presents both threat and opportunity, which collectively represent risk, with the potential to erode or enhance value. Risk management enables management to effectively deal with uncertainty and associated risk, enhancing the capacity to build value. 
Mining companies are expected to show that they are committed to managing the potential risks in a continuous, proactive and systematic way through competent risk management. This requires the integrated application of high-quality risk management practices and processes to all facets of the business by all levels of management.

Risk-taking is essential to value creation, since virtually any activity that seeks to create or increase value also carries some degree of risk. This is particularly valid for mining as both the risks and rewards are typically large and require substantial attention. Gold mining is perhaps becoming increasingly risky as economically viable resources decline and new challenges have to be considered.

Risk management is inherently about the management of unplanned events; events that could occur within a company, surrounding environment, community, political domain, regulatory sphere, or world markets, among other things, and which have the potential to impact on the viability of the company. The process of assessing and managing risks is aimed at reducing the likelihood that such negative events could occur, whilst increasing the likelihood of positive outcomes.

\section{A2.1 Risk management overview}

The underlying framework on which the GRM tool was built consists of three elements taken from typical risk-management processes used in the mining industry:

- Risk matrix: The communication of risk needs to be in a familiar format that can be understood by both technical and non-technical employees. As a rule, every mining company will have its own risk matrix, adopted from the various versions of risk matrices available in the mining industry.

- Risk assessment: The assessment of hazards and their impacts needs be a rigorous, recognised, repeatable process. The challenge is to ensure a comprehensive coverage of the geotechnical engineering process, without getting stuck in a mire of detail.

- Risk management: The management or treatment of risks is a critical process that requires a structured approach to reporting, monitoring and reviewing.

In order for this risk management overview process to remain effective, regular benchmarking of the risk-assessment and risk-management processes against that used in the mining industry is required.

\section{A2.2 Risk matrix overview}

A matrix provides an acceptable means for assessing and reporting material risk in a company; it represents a 'common risk language' so that senior management can compare like-with-like and ensure that the most important risks receive priority. Using the correct corporate risk matrix also means that company values that may be hardcoded into corporate risk matrices are adhered to. It can be used for all risk-ranking processes within a company. It should be noted that the risk matrix adopted does not replace other more detailed, rigorous risk-analysis techniques that may be appropriate to properly evaluate the risk, particularly for high-consequence events.

The risk matrix permits an assessment (refer to Figure A2-1) of any risk on the basis of its consequence and likelihood. The consequence and likelihood associated with a risk are effectively maintained separately and are never multiplied when using the risk matrix for the reason that we must not lose sight of high-consequence, low-probability events.

For example, a 'red' risk could have a single fatality or multiple fatalities associated with it. The unique risk index derived from the matrix indicates both the row (consequence) and column (likelihood). 


\begin{tabular}{|c|c|c|c|c|c|c|c|c|}
\hline Extreme & c6 & $-\mid+21$ & $-/+30$ & $-/+32$ & $-1+34$ & $-1+35$ & $-1+36$ & Exceptional \\
\hline Major & c5 & $-/+17$ & $-1+27$ & $-1+28$ & $-1+29$ & $-\mid+31$ & $-1+33$ & Substantial \\
\hline High & $c 4$ & $-/+14$ & $-1+22$ & $-1+23$ & $-/+24$ & $-1+25$ & $-1+26$ & Valuable \\
\hline Moderate & c3 & $-1+8$ & $-/+15$ & $-/+16$ & $-\mid+18$ & $-/+19$ & $-1+20$ & Significant \\
\hline Minor & $C 2$ & $-1+2$ & $-1+9$ & $-/+10$ & $-/+11$ & $-/+12$ & $-/+13$ & Useful \\
\hline Insignificant & $C 1$ & $-/+1$ & $-1+3$ & $-/+4$ & $-/+5$ & $-1+6$ & $-/+7$ & Insignificant \\
\hline & & $L 1$ & $L 2$ & $L 3$ & $L 4$ & $L 5$ & $\angle 6$ & \\
\hline & & $\begin{array}{l}\text { Almost } \\
\text { mpossible }\end{array}$ & $\begin{array}{c}\text { Very } \\
\text { unlikely }\end{array}$ & Unlikely & Likely & $\begin{array}{l}\text { Very } \\
\text { likely }\end{array}$ & $\begin{array}{l}\text { Almost } \\
\text { certain }\end{array}$ & \\
\hline
\end{tabular}

Figure A2-1 AngloGold Ashanti risk assessment and reporting matrix (horizontal axis - likelihood; vertical axis - consequence)

\section{A2.3 Detail on risk assessment and risk management}

The key objective of a risk-management system is to ensure that a mining company operates safely at known and acceptable levels of risk to ensure that it meets or exceeds its business objectives. In this case, the GRM needs to fulfil the role of the risk-management system for geotechnical risk on a mine. The risk-management system in this paper adopts the ISO31.000 (International Organization for Standardization 2008) approach as a basis. This approach comprises two components as follows; also see Figure A2-2:

- Risk assessment, which entails the context setting, identification, analysis and treatment evaluation of risks.

- Risk management, which entails the determination of risk response measures, reporting and escalation, monitoring and review, and measurement and assurance phases.
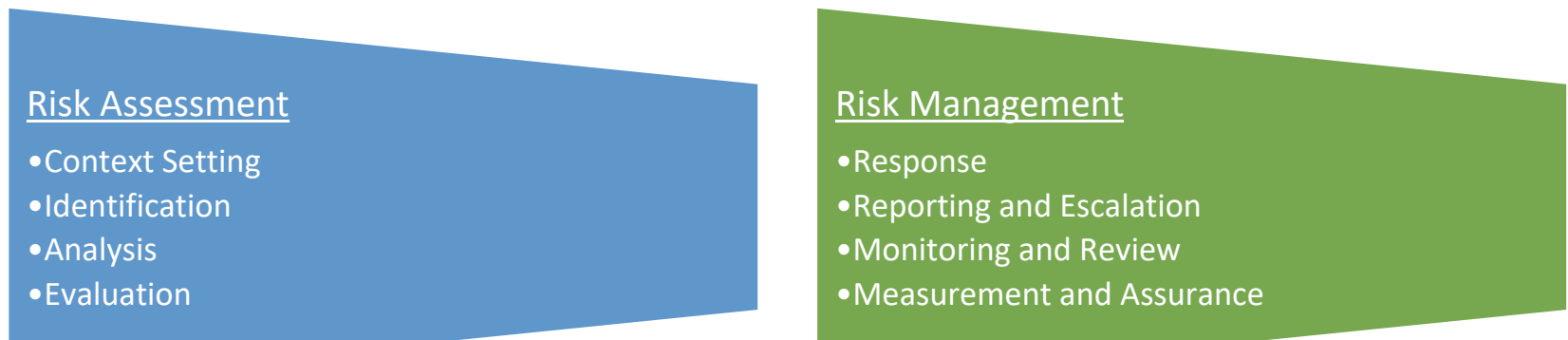

Figure A2-2 Risk assessment and risk management components of the risk management system approach as followed in ISO31.000 (International Organization for Standardization 2008)

The paper provides a brief summary of each of these phases (after Harley 2011). However, readers are encouraged to familiarise themselves with the basis of each. 


\section{A2.3.1 Establish context}

'Establishing the context' is about placing the risk assessment into perspective to ensure that the assessment is focused and elicits risks that are pertinent to the business objectives. This is necessary because risks that are relevant to one desired outcome could be different for another outcome.

The following should be considered and documented during the 'establish the context' phase:

- The reasons for conducting the risk assessment.

- Those affected by the process and the outcomes of the risk assessment.

- Other work being undertaken that could impact the risk assessment.

- Coordination with other risk work relevant to the particular scenario.

\section{A2.3.2 Identification}

Risk identification is the first step in the risk assessment process. A systematic and documented approach should be adopted for risk identification essentially to determine what, how, where, and when events could happen that could impact on the objectives.

When identifying risks, it is worth remembering the following:

- Threats ('negative' or 'downside' risks): Risks that have the potential for adverse consequences and that can be addressed by 'termination' (elimination, redesign, avoidance or substitution), 'treatment' (mitigation or control), 'transference', or, as a last resort, 'toleration' (retention or acceptance).

- Opportunities ('positive' or 'upside' risks): Risks that have the potential for beneficial consequences and that can be addressed by 'exploiting', 'sharing', 'maximising' or 'enhancing').

It is recommended that separate assessments are conducted for threats and opportunities, as they require different thought processes, and better results may be achieved by adopting distinct mindsets for each assessment. During the identification phase, discipline should be applied to measuring a risk's root cause as well as linking it with its process source and current treatment (control) effectiveness.

\section{A2.3.3 Analysis}

The next step is risk analysis, that takes place once the risks have been identified and documented. Risk analysis is the process of considering the following:

- Current treatments (that are in place along with their effectiveness).

- Pre-treatment state.

- Post-treatment state.

The current treatments (controls) that are in place need to be documented, along with their effectiveness. The reason for this is that, should they not be effective, the risk levels will revert to the pre-treatment level and are, therefore, often critically important. Current treatment designed for threats should be aimed at ensuring that the reliability of the current treatment is appropriate given the potential consequences associated with the threat. As the consequences increase, there is a need to have a greater degree of confidence that the treatment will be effective. When designing a new system or facility, or reviewing the current treatments, the traditional hierarchy of controls should be used to maximise the effectiveness of the current treatment as follows:

- Eliminate the threat.

- Minimise or replace the threat.

- Control the threat using: 
○ Engineered devices.

- Physical barriers.

- Procedures.

- Personal protective equipment (PPE).

- Warning and raising awareness.

Current treatments are in place to prevent the risk from materialising (reducing the likelihood) and/or to mitigate the risk should it materialise (reducing the consequences). Generally, a layered defence system of current treatments is adopted. The types of defence are:

- Group.

- Technical.

- Administrative.

- Individual.

Critical current treatments are those that are critical to the integrity of the system. For example, brakes are critical to the safety of a car; whereas airbags are desirable but not critical. The options at the top of the following list are most effective, as they address the hazard rather than just reduce the risk. The hierarchy of controls (Figure A2-3) is as follows:

1. Eliminate the hazard altogether. For example, seal off the hazardous workings.

2. Substitute the hazard with a safer alternative. For example, abandon hazardous workings and replace with a safer one.

3. Isolate the hazard from anyone who could be harmed. For example, demarcate and restrict access to the hazardous zones within the workings.

4. Use engineering controls to reduce the risk. For example, install surface support and reinforcement to control the hazardous zones within the workings.

5. Use administrative controls to reduce the risk. For example, train workers to identify hazards within the workings.

6. Use PPE. For example, wear gloves and hardhat when accessing workings.

The aim should be to eliminate the hazard altogether where practical. Where the hazard cannot be eliminated, more than one option should be used to reduce the risk to acceptable levels.

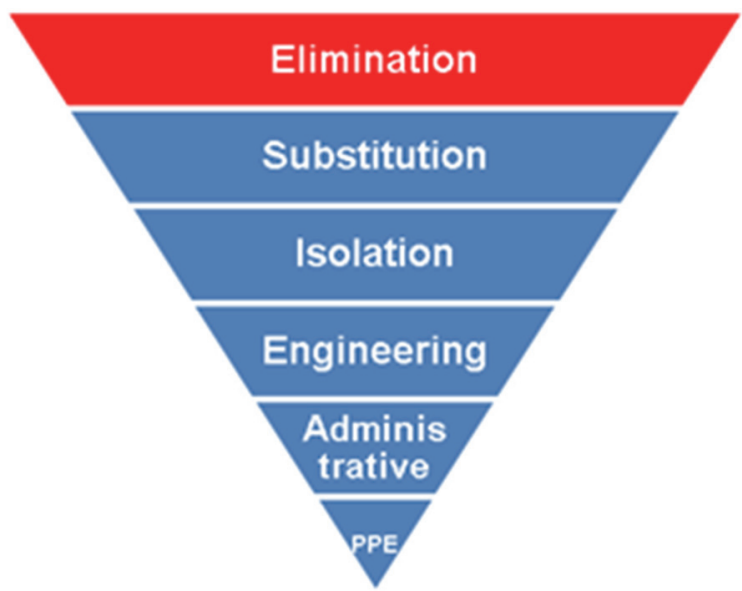

Figure A2-3 Hierarchy of controls - four options at top address the hazard rather than just reduce the risk 
Consideration and allocation of likelihood and consequence ratings to each risk occurs next. This needs to be undertaken in two stages; the first being consideration of the 'pre-treatment' state, and the second the 'post-treatment' state. It is important to understand the difference between these states; that is:

- 'Pre-treatment' is the risk state assuming that the 'current (at the time of the assessment) treatment' (control) is not in place or is not effective.

- 'Post-treatment' is the risk state assuming that the 'current (at the time of the assessment) treatment' (control) is effective and can be relied upon to remain effective. The post-treatment risk state is effectively the residual risk.

For both of these stages, a suitable risk matrix should be used to consider and assign consequences and likelihoods to every risk identified. The left-hand side of the matrix (refer to Figure A2.1) is used during the consideration of the consequences of threats, and the right-hand side for opportunities, with the central matrix applicable to both. Once the consequences have been determined and recorded, the next step is to consider the likelihood of the risk and its consequence(s) materialising. This is difficult to get right in most cases. The best approach to simplify this is to split the likelihood into its two components of the probability of event occurring and the exposure probability.

The probability of the event occurring should be established, as well as the probability that the consequence would materialise. An example is the risk of a worker being injured in an open pit through failure of the pit wall. The probability of the pit wall failing would be determined from geotechnical investigation and modelling. The probability of a worker being in the pit would be determined from the length of time that he/she spends in the pit, within the area of influence of a wall failure. These two probabilities are multiplied to give the overall likelihood of the risk and its consequence materialising.

The event probability and the exposure probability of each consequence materialising should be determined and recorded as part of the assessment process. These are typically determined from historical data, detailed analysis, and/or expert judgement. Although this approach to risk assessment is qualitative and can be subjective in many situations, its main value lies in the speed with which risks can be assessed and ranked. It should be noted that this type of assessment is only appropriate for the initial classification and ranking of risks and that additional and more thorough work needs to be undertaken for the majority of the greater risks.

\section{A2.3.4 Evaluation}

The evaluation stage compares risks with the risk thresholds and appetite to determine whether a risk is acceptable or unacceptable. If unacceptable, the risk evaluation step should consider and determine the level of attention required for the risk. The evaluation should take account of the fact that the risk criteria for the assessment could be different to the group thresholds and that lower thresholds might be appropriate.

\section{A2.3.5 Risk response}

The risk response step determines how best to treat the risks that are above the risk thresholds. Risk-response objectives are essentially to reduce the severity and/or probability of threats and to increase the magnitude likelihood of opportunities. The aim of any threat response/reduction task, or combination of tasks, should be to mitigate the threat to an acceptable level, typically to below or equal to the group threshold level. The aim of any opportunity augmented task, or combination of tasks, should be to harness the opportunity or to increase the risk classification as far as reasonably possible.

\section{A2.3.6 Reporting and escalation}

Risk information should be reported and communicated so that it can inform better decision-making and ensure an appropriate risk response. For reporting to be relevant and effective, risk information needs to be accurate and up-to-date.

From a risk management perspective, it is essential that incident information is used to inform the risk-management system. Risks that have materialised (incidents) need to be linked back to the hazards, 
firstly to determine if the risks were identified correctly or at all, and secondly, if not identified, the risks should be assessed for applicability and level at each relevant operation or project as appropriate.

In situations of escalating risk, risk aggregation, near-misses, issues or disagreements around risks, current treatment effectiveness, adequacy of risk response tasks, etc., it is important for a company to establish a suitable escalation protocol. This would typically start with operational or project risk owners, progressing up to an executive risk owner.

\section{A2.3.7 Monitoring and review}

Risk-performance monitoring, measurement, assurance and review involve the overall tracking and testing of the risk management system and its outputs, and should be undertaken on an ongoing basis via routine monitoring activities, separate evaluations, and benchmarking.

Ongoing monitoring and review are essential parts of the risk management system, for the purposes of:

- Analysing and learning from events, changes and trends.

- Detecting changes in the external and internal context including changes to the risks themselves requiring revision of the risk's current treatments and priorities.

- Ensuring that current treatments and risk response tasks are effective in design and operation.

- Identifying emerging risks.

Actual progress in the implementation of risk response tasks and plans provides a performance measure and is incorporated into the mine or group's performance management and measurement, and internal and external reporting activities.

Monitoring and review is achieved through communication, observation and examination of risk information (risk status, current treatments, and response tasks) and dynamics (incidents, changes, velocities, aggregation, systemic and emerging risks) to the appropriate risk management levels in order to alert management as to when risk management plans should be implemented or adjusted.

\section{A2.3.8 Measurement and assurance}

Risk measurement is undertaken by benchmarking measurement against predetermined performance indicators and specific tests. Benchmarking should be undertaken regularly at corporate, regional, operational and project levels to measure the internal risk processes through identifying, understanding and adapting outstanding practices from industry considered to be best-in-class. Benchmarking of other companies or projects, including some outside the mining industry, is essential to ensure that the risk program represents best-practice by:

- Determining which parts or elements within the risk management system are to be benchmarked: those that will benefit most from the benchmarking process, based upon the cost, importance and potential of changes following the study.

- Identifying key factors and variables to measure.

- Selecting the best-in-class companies or projects for each area to be benchmarked: those companies or projects that perform each activity very effectively and efficiently.

- Measuring the performance of the best-in-class companies or projects for each benchmark being considered.

- Measuring your own performance for each variable and comparing the results to determine the gap between yourselves and the best-in-class examples.

- Specifying those programs and actions to meet and surpass the competition based on a plan developed to enhance those areas that show potential. 
- Implementing these programs by setting specific improvement targets and deadlines.

- Developing a monitoring process to review and update the analysis over time, and to provide a basis for monitoring, revision and recalibration of measurements in future benchmarking studies.

Risk measurement is also undertaken via the setting of, and measurement against, key performance indicators. These are identified and set for the following:

- Risk identification.

- Mapping of risks to internal controls, budgets and resource allocation.

- Review and update.

- Effectiveness of internal controls and current treatments.

- Changed behaviour and resources as a result of risk.

Tests of current treatment performance should be undertaken that examine whether or not the current treatment:

- Performs as designed.

- Achieves the required levels of effectiveness, reliability and availability consistent with the criticality of the associated activity.

- Alternative, more cost-effective current treatments.

Current treatment effectiveness should be regularly checked via:

- A continuous monitoring program on a day-to-day basis that is embedded in the place and methods of work.

- Line management reviews that utilise current treatment self-assessments driven by the risk profile and management's span of control.

- Third party audits which are to include internal and external audits, sampling and verification aimed at policy development and standard compliance.

Tests of risk-mitigation tasks should be undertaken to demonstrate that the tasks have been carried out properly, and are effective in reducing threats and harnessing opportunities.

\section{References}

Accreditation Board for Engineering and Technology 1987, Fifth Annual Report, Accreditation Board for Engineering and Technology Washington DC.

Basson, FRP \& Dunn, MJ 2009, Numerical Modelling Guidelines for Underground Mines, internal document, Newmont Asia Pacific.

Bieniawski, ZT 1991, 'In search of a design methodology for rock mechanics', in J-C Roegiers (ed.), Rock Mechanics as a Multidisciplinary Science: Proceedings of the 32nd US Symposium on Rock Mechanics, A.A. Balkema, Rotterdam, pp. 1027-1036.

Bieniawski, ZT 1992, 'Invited paper: Principles of engineering design for rock mechanics', in JR Tillerson \& WR Wawersik (eds), Rock Mechanics: Proceedings of the 33rd US Symposium on Rock Mechanics, A.A. Balkema, Rotterdam, pp. 1031-1040.

Davies, E 1967, Report of the Tribunal Appointed to Inquire into the Disaster at Aberfan on October 21st 1966, Her Majesty's Stationery Office, London, pp. 131-132.

Hamman, ECF 2003, 'A methodology for geotechnical hazard and risk reviews on open pit mines', Proceedings of The First African Young Geotechnical Engineers Conference, International Society for Soil Mechanics and Geotechnical Engineering, London.

Hamman, ECF 2009, 'Qualitative geotechnical hazard and risk assessment', Proceedings of the 2009 International Symposium on Rock Slope Stability in Open Pit and Civil Engineering, University de los Andes, Santiago.

Hamman, ECF, du Plooy, DJ \& Seery, JM 2017, 'Data management and geotechnical models', J Wesseloo (ed.), Proceedings of the Eighth International Conference on Deep and High Stress Mining, vol. 2, Australian Centre for Geomechanics, Perth, pp. 461-488.

Harley, E 2011, Group Risk Management Guidelines, internal document, AngloGold Ashanti.

Harr, ME 1996, Reliability-based Design in Civil Engineering, Dover Publications, New York.

International Organization for Standardization 2008, ISO/DIS 31.000: Risk Management Principles and Guidelines on Implementation, International Organization for Standardization, Geneva. 
Kamien, DJ 1995, Introduction to Probability and Reliability Methods for use in Geotechnical Engineering, Engineering Technical Letter No. 1110-2-547, The US Army Corps of Engineers, Washington DC.

Lilly, PA 2000, Risk Analysis and Decision Making, unpublished Master of Engineering Science course notes, Curtin University, Perth. McMahon, BK 1978, Application of Rock Mechanics to Mine Design, Australian Mineral Foundation, Glenside.

Naismith, WA 1998, Hazard Identification for Rock Engineering, SIMRAC Report - GAP 339, Department of Mineral and Energy Affairs, Pretoria.

Read, JRL 2009, 'Data uncertainty', in JRL Read \& P Stacey (eds), Guidelines for Open Pit Slope Design, CSIRO Press, Collingwood, pp. 213-220.

Read, JRL \& Stacey, P 2009, Guidelines for Open Pit Slope Design, CSIRO Press, Collingwood.

Silwamba, C \& Chileshe, PKR 2016, 'Radar slope management at Nchanga open pit mine Zambia: footwall failure of November 2014', International Journal of Research Science and Management, May 2016, pp. 10-22.

Stacey, TR 2009, 'The importance of engineering design with regard to safety in mining', Proceedings of the International Symposium on Hard Rock Safe Safety Conference, South African Institute of Mining and Metallurgy, Johannesburg, pp. 291-304.

Sullivan, TD 2006, 'Pit slope design and risk - a view of the current state of the art', Proceedings of the 2006 International Symposium on Stability of Rock Slopes in Open Pit Mining and Civil Engineering, South African Institute of Mining and Metallurgy, Johannesburg, pp. 51-78.

Terbrugge, PJ, Wesseloo, J, Venter, J \& Steffen, OKH 2006, 'A risk consequence approach to open pit slope design, Proceedings of the International Symposium on Stability of Rock Slopes in Open Pit Mining and Civil Engineering, South African Institute of Mining and Metallurgy, Johannesburg, pp. 81-96.

Wiles, TD 2006, 'Reliability of numerical modelling predictions', International Journal of Rock Mechanics and Mining Sciences, vol. 43, no. 3, pp. 454-472. 